\title{
The Relation of Ultraviolet Radiation and Multiple Sclerosis in Newfoundland
}

\author{
JS Sloka, WEM Pryse-Phillips, M Stefanelli
}

\begin{abstract}
Background: It has been thought that the occurrence of multiple sclerosis (MS) could be associated with daily ultraviolet exposure. In this study we investigated the geospatial association between average daily ultraviolet B (UVB) irradiance and MS prevalence in Newfoundland and Labrador (NL), Canada. Methods: A complete list of patients diagnosed with MS in the province of NL was constructed. Places of habitation from birth to diagnosis were ascertained by mailout survey. Results: A 74\% rate of return on the survey results was obtained. A plot of the average daily erythemal UV over the available five years (1998-2002) shows that the distribution of MS follow a north-south gradient. Average daily UVB measurements are lower in the higher latitudes. A statistically significant negative correlation of MS incidence with erythemal UVB was found that is stronger than the correlation using latitude. This correlation appears to be strongest in the first year of life and declines when subsequent years are examined up to age ten. No significant correlation was found for the subjects' locale of habitation at the time of their first MS attack. Conclusions: This study suggests that UVB radiation may contribute to the pathogenesis of MS.
\end{abstract}

RÉSUMÉ: La relation entre le rayonnement ultraviolet et la sclérose en plaques à Terre-Neuve. Contexte : Certains croient que l'apparition de la sclérose en plaques (SEP) pourrait être associée à l'exposition quotidienne aux rayons ultraviolets. Nous avons étudié l'association géospatiale entre le rayonnement ultraviolet B (UVB) quotidien moyen et la prévalence de la SEP à Terre-Neuve et au Labrador, au Canada. Méthodes : Nous avons établi une liste complète des patients chez qui un diagnostic de SEP a été posé dans cette province. Les lieux de résidence depuis la naissance jusqu'au moment du diagnostic ont été documentés au moyen d'un questionnaire par courrier. Résultats : Le taux de participation a été de $74 \%$. Un diagramme illustrant le rayonnement ultraviolet quotidien moyen provoquant l'érythème au cours des cinq années pour lesquelles l'information était disponible (1998 à 2002) montre que les mesures UVB quotidiennes moyennes sont plus faibles aux plus latitudes élevées. Par contre, la distribution de la SEP a un gradient nord-sud. Nous avons constaté que la corrélation négative entre l'incidence de la SEP et le rayonnement UVB érythématogène est plus forte que la corrélation entre l'incidence de la SEP et la latitude. Cette corrélation semble être plus forte pour les premières années de vie et diminue quand on examine les années de vie ultérieures jusqu'à l'âge de dix ans. Nous n'avons pas constaté de corrélation significative avec le lieu de résidence au moment de la première poussée de SEP. Conclusion : Cette étude suggère que le rayonnement UVB puisse contribuer à la pathogenèse de la SEP.

Can. J. Neurol. Sci. 2008; 35: 69-74

An incidence and prevalence study of Multiple Sclerosis (MS) in the Canadian province of Newfoundland and Labrador (NL) has recently been completed, demonstrating a population prevalence (MS) of 94.4 per 100,000..$^{1}$ Newfoundland and Labrador is Canada's easternmost province and its population is unusual in the investigation of complex disease ${ }^{2}$ as a result of its settlement history, its subsequent founder effect, and its geographical isolation. ${ }^{3}$ The island portion of the province (Newfoundland), lies between latitudes 46 and $52 \mathrm{~N}$ and longitudes 52 and 59W. It has an area of $108,860 \mathrm{~km}^{2}$ and a population of 521,986 (49\% urban) ${ }^{4}$ settled largely along the sea coast. Approximately $60 \%$ of the inhabitants live in settlements with populations of less than $2500^{4}$ and about $98 \%$ of the population is of English or Irish descent. ${ }^{4}$

From the Faculty of Medicine (Neurology) (JSS), Memorial University of Newfoundland; Faculty of Medicine (Neurology) (WEMPP, MS), Health Sciences Center, St. John's, Newfoundland, Canada.

Received July 10, 2007. Final Revisions Submitted October 26, 2007. Reprint requests to: J Scott Sloka, Faculty of Medicine (Neurology), Memorial University of Newfoundland, 108 Moss Heather Dr., St. John's, Newfoundland, A1B 4S1, Canada 
An investigation of the distribution of MS in NL concluded that both genetic and environmental factors contribute to the observed geospatial distribution of the disease. ${ }^{5}$ The hypothesized environmental contribution was observed to follow a north-south gradient, modeled using strictly latitude as the modifying environmental parameter. This north-south gradient is also observed globally when the results of all prevalence studies published in the last five years are plotted against latitude (Figure 1). Since latitude itself is unlikely to be an independent risk factor for MS, environmental correlates to latitude may be found to contribute to susceptibility. One candidate environmental correlate is ultraviolet B (UVB) radiation, which follows a northsouth gradient across Newfoundland latitudes. UVB (280 to 315 $\mathrm{nm}$ ) peripherally converts 7-dehydroxycholesterol to vitamin D in the epidermal and dermal layers and is the primary source of vitamin D in humans. ${ }^{6}$ Due to the changing angle of declination of the sun, vitamin D insufficiency is common in the winter months in latitudes north of $42^{\circ} \mathrm{N}$ latitude. ${ }^{7}$ Vitamin D deficiency has previously ${ }^{8}$ and recently been studied as a potential contributing factor in the pathogenesis of MS.9-11 The current study examines the geospatial relation between UV radiation and the incidence of MS in Newfoundland.

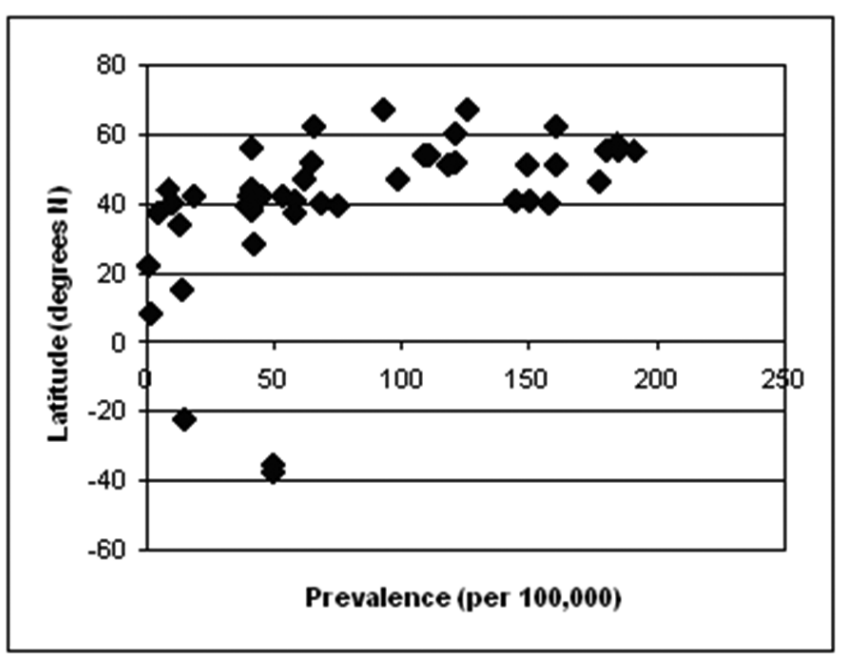

Figure 1: Prevalence versus latitude for all studies using the equator as the $x$ scale reference. Negative latitudes represent degrees south. This plot visually reasserts a correlation between increasing prevalence and increasing latitude. (Studies published 1999-2004. $)^{12}$

\section{METHODS}

An incidence and prevalence study of MS was conducted for 2001 and a database was created, with information for 493 confirmed cases. ${ }^{1}$ The case ascertainment methodology has been reported in the incidence and prevalence study. ${ }^{1}$ Briefly, case finding of MS patients was conducted by hand searching for patients with a diagnosis of MS through the patient records of the neurologists practicing in the province, although all neurologists have been referring patients with new MS diagnoses to the University MS clinic for several years. The accuracy of the search was further enhanced by accession to provincial billing records for the fiscal years April 1, 1996 to March 31, 2003, made possible through an official government Order in Council to the provincial government Medical Care Plan (MCP). The study received ethical approval from the university's Human Investigation Committee. Three previous databases (one from the previous 1984 study, one from a localized study in Gander, $\mathrm{NL}$, and one kept in Vancouver for genetic research) were combined to determine both current and historical diagnoses.

Once an initial list was generated, both neurologist and hospital patient records were reviewed to confirm the diagnosis of clinically definite MS. Patient records were reviewed and only those patients that met the Poser criteria were included. Patients with clinically isolated syndromes, primary progressive multiple sclerosis (PPMS), and isolated optic neuritis were excluded. PPMS was excluded from the patient group since it is not known if the effects of vitamin D may alter its clinical course differently from the relapsing remitting type. All confirmed diagnoses demonstrated clinical evidence of two attacks separated in time and space (usually supported by clinical laboratory evidence) as judged by the attending neurologist, and were consistent with the Poser committee criteria. ${ }^{13}$ Poser criteria were used for all patients to keep the criteria consistent across the time period. Once the list of diagnosed patients was confirmed, a search for death notices of these patients was conducted through the Newfoundland and Labrador Center for Health Information and the Newfoundland and Labrador Vital Statistics Division. Given such methods, it is probable that near- complete case ascertainment was achieved for diagnosed MS in the province ${ }^{1}$ as of that time.

In October 2003, a survey was mailed to the living diagnosed patients whose current addresses could be confirmed, with a subsequent mailing to those that had not responded after six weeks. This survey asked specific questions relating to all places of residence from birth to diagnosis of MS (age and habitation history).

Previous studies of the age at which people migrate have shown that a general age range might be important in the natural history of the disease in terms of susceptibility to an environmental pathogen. Many studies on age-at-migration suggest that either a general age range ${ }^{14-20}$ or a "critical age" at migration alters the risk of disease, and this critical age tends to be close to the age of $15 .{ }^{15-17,20}$ (Thus, populations migrating before the age of 15 from one region to another would acquire the risk of susceptibility characteristic of the new region). The implication of these studies is that the risk of acquiring MS may largely be determined by the age of 15 years. Therefore, the geospatial distribution of MS was determined for each of the 79 Newfoundland census subdivisions, localizing each patient's residence prior to the age of 15 . Three different time references were used: locale of habitation for the first year of life, weighted average of locale of habitation over the first ten years of life (weighting each year of incidence at 0.1 ), and locale of habitation during first attack.

This was conducted with the approval of the Human Investigations Committee of Memorial University of Newfoundland. 


\section{Satellite Data}

The Total Ozone Mapping Spectrometer (TOMS) is a satellite-mounted optical sensor used to measure the albedo (reflected power) of the earth's atmosphere at six narrow spectral bands, including several ultraviolet B (UVB) bands. Erythemal exposure is a measure of the potential for biological damage due to solar ultraviolet radiation. Total Ozone Mapping Spectrometer erythemal exposure is calculated using UV irradiance reaching the surface of earth weighted by the susceptibility of Caucasian skin to sunburn (erythema) ${ }^{21}$ and preferentially weights those frequencies that cause peripheral conversion of vitamin D in the skin.

Daily erythemal UV data was acquired from the NASA TOMS project from the years 1998 to 2002 with a resolution of approximately $85 \mathrm{~km} \mathrm{x} 100 \mathrm{~km}$ for Newfoundland latitudes. A computer program was developed by the lead author (JSS) to read in the daily data and to calculate a linearly interpolated measurement of daily erythemal UV for each census subdivision. The latitude and longitude of the centroid of each census subdivision was used as the co-ordinates from which to interpolate. The average daily UV data over the period from Jan 1, 1997 to Dec 31, 2002 was then calculated.

\section{Statistical Analysis}

An analysis of the spatial variation of disease was conducted over 79 census consolidated subdivisions within this province. Since area-specific numbers of cases are often small, traditional statistical methods of analysis tend to yield very extreme rates due to random variation. Therefore, the direct mapping of incidence rates may lead an observer to draw incorrect conclusions due to visual attention to the extremes. A hierarchical Bayesian approach overcomes this problem by using the risk information in neighbouring areas to reinforce the incidence estimates (a conditional autoregressive model). ${ }^{22}$ This method assumes that the underlying relative risks follow an a priori probability distribution. An estimate that compromises between the area-specific risk and the weighted average of the neighbouring areas' risks is simulated. ${ }^{23-26}$ Extreme estimates are "smoothed" more, (i.e. are pulled more towards the mean) when the original number of counts is small without local evidence supporting the extreme value. This Bayesian estimate may better represent the true geographical risk variation. ${ }^{27}$ Bayesian analysis has been used to model the distribution of MS in Sardinia..$^{28}$

A binomial model was assumed to obtain Bayesian estimates through Gibbs sampling 26,29 on BUGS software ${ }^{30}$ and included both a spatially unstructured extrabinomial variation (heterogeneity) and a spatially structured variation (clustering). ${ }^{27,31}$ Specifically, the conditional autoregressive model was used.$^{27}$ Convergence at 30,000 iterations was checked by visual examination of sample traces by Geweke's diagnostic ${ }^{32}$ implemented in the CODA software. ${ }^{33}$ A burn in of 30,000 iterations was performed and discarded, and a subsequent 20,000 iterations were used in the final analysis.

Two different hyperprior distributions were compared for simulation. One was based on a model as $\Gamma(1,1)$ and the other a model as $\Gamma(0.5,0.0005)$ as per Bernardinelli et al. ${ }^{34}$ There was very little variation in the results between distribution choices, so the $\Gamma(0.5,0.0005)$ distribution was used..$^{35}$
Correlation between two geospatial variables is demonstrated using the following relation. ${ }^{36,37}$

$$
\log \left(\theta_{i}\right)=\rho+\beta x_{i}+u_{i}+v_{i}
$$

Where $\theta$ is the relative risk of measuring MS incidence in the ith census subdivision, $\rho$ is a constant, and $\beta$ is a vector of parameters representing the residual correlation between explanatory environmental variables $\mathrm{x}_{\mathrm{i}}$ (ie the UV irradiance) and the relative risk of MS in that census subdivision after the heterogeneity of local, $\mathrm{u}_{\mathrm{i}}$, and global, $\mathrm{v}_{\mathrm{i}}$, variation is accounted for. A 95\% credible interval range for the sampling of $\beta$ is used. An $\alpha$ of 0.05 is used for tests of significance.

\section{RESULTS}

In October 2003, 438 addresses were confirmed for the patients that were known still to be alive and these patients were mailed surveys. After two mailings, 328 surveys were returned (a $74 \%$ rate of return). There were no differences between the patients that returned the survey and the patients that did not in terms of average age ( $45.7 \mathrm{y}$ vs $45.2 \mathrm{y}: \mathrm{p}=0.53$ ), female to male ratio (2.72:1 vs 2.86:1: $\mathrm{p}=0.76)$, age of first symptoms (32.2 y vs $32.4 \mathrm{y}: \mathrm{p}=0.81)$ and proportion of those patients with relapsing remitting MS (83\% vs 83\%: $\mathrm{p}=0.97$ ), respectively. The geospatial distribution of the relative risk of MS incidence at age ten years for all 328 respondents is shown in Figure 2 after Bayesian analysis. Generally, most of the southern portions of the province have an average relative risk whereas many of the more northern census subdivisions have a higher than average risk after Bayesian estimation has been performed.

A plot of the average daily erythemal UV over the available five years (1998-2002) is shown in Figure 3. This distribution is more clearly north-south, with higher latitudes having lower average daily UV measurements.

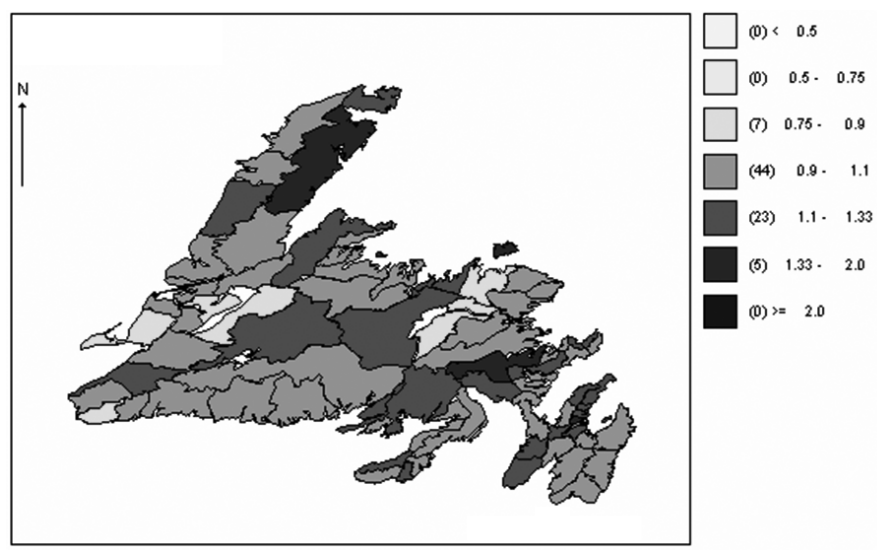

Figure 2: Regional relative risk of MS incidence for each census subdivision for all 328 survey respondents at age ten years. This plots the incidence of MS across the 79 census subdivisions where patients were living when they were aged ten. The bracketed numbers in the legend are the number of CCSs in the given range. 


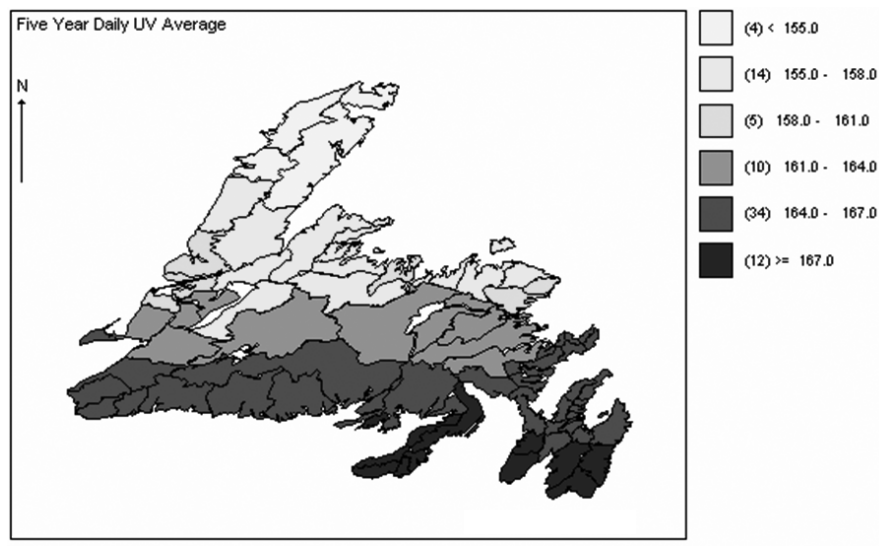

Figure 3: Average daily erythemal UV over the available five years (1998-2002), calculated using linear interpolation of daily TOMS data from the latitude and longitude of the centroids of each census subdivision.

Ecological (covariance) analysis using the average daily erythemal UV for each subdivision as covariates for the risk for MS in each NL census subdivision for the first year of life allows us to calculate a mean covariate coefficient $(\beta)$ from equation (1) above of -0.0686 (95\% CI -0.0987 to -0.0234 ). The distribution of MS incidence was age-sex standardized for this estimation. This ecological analysis indicates that the risk of MS is negatively correlated with the average daily erythemal UV, and since the $95 \%$ credible interval does not include 0 (zero) this correlation is statistically significant. The contribution is small (given the low value of $\beta$ ), implying that other factors (such as genetics) may also contribute. In order to measure variability with select habitation age, a similar analysis for locale of habitation over the first ten years of life was performed. The covariate coefficient of -0.0285 ( $95 \%$ credible interval -0.129 to 0.0298 ) suggests that the correlation is not as strong for this weighted average. The fact that there was some intra-regional migration, suggests that the previously-observed low intraregional migration rates ${ }^{38-39}$ may be changing. Additionally, a separate analysis for locale of habitation during first attack showed a non-significant correlation of 0.0290 (95\% CI -0.004 to 0.0684 ).

Covariate analysis using latitude vs MS locale of habitation at age one also reveals a significant correlation of 0.1307 (95\% CI 0.0440 to 0.2132 ). In this case, the correlation is positive instead of negative. Since the correlation coefficient represents the scaled contribution of the variable (UVB, latitude) to the observed process (MS incidence), comparison of two contributions is achieved by scaling one variable to meet the mean of the other (as in equation 1 above). After this scaling is performed, the average daily erythemal UV covariate coefficient becomes -0.2309 (95\% CI -0.3322 to -0.0788 ), suggesting that the contribution of the average daily erythemal UV accounts for more of the variation of MS incidence than does simple latitude.

A type of sensitivity analysis was accomplished by selectively moving people from the north to the south of the province (effectively reducing any north-south gradient) and re-estimating the correlation coefficient. Approximately five people would have to be moved from the north to the south of the island in order to change the correlation coefficient from significant to non-significant.

\section{Discussion}

This ecological study uses Bayesian analysis to suggest a relation between satellite erythemal UVB data and the incidence of MS in Newfoundland. The role of solar radiation in the pathogenesis of MS was first proposed in the $1960 \mathrm{~s}^{8}$ with the role of vitamin $\mathrm{D}$ itself being suggested a decade later. ${ }^{40}$ The impetus of studying the role of solar radiation, and more specifically UVB, is derived from the observation that MS tends to follow an equatorofugal gradient ${ }^{41}$ (Figure 1). Surface UVB radiation also follows this pattern, but in an inverse manner. Multiple Sclerosis has been negatively associated with residential exposure to sunlight ${ }^{42}$ and a negative correlation between UV radiation and MS prevalence has been found in Australia ${ }^{43}$ Recent evidence also suggests that increased sun exposure during the ages 6-15 years is associated with a decreased risk of $\mathrm{MS}^{44}$

We found that an environmental contribution of UVB radiation is negatively associated with the risk of MS in the Canadian province of Newfoundland and Labrador. This correlation is stronger than is found when only latitude is tested, and this correlation is significant for locale of habitation for age one years, though less so for a weighted average over the first ten years of life, and not at all significant for locale of habitation at first symptoms (at age 31 years on average). This suggests, for our population, that a lack of exposure to UVB radiation in childhood may be a risk factor for MS later in life. As well, because the effect is greater at younger ages (especially for locale at birth), one may hypothesize a potential for an intrauterine contribution to the disease process relating to vitamin D insufficiency in the mother. Whether the effect is maximal during the development of myelination or after myelination has occurred is speculative.

The non-significance of effect with age at first attack could possibly reflect the migration of young adults to major centers for education and work over the last ten years of economic difficulty within the province. The major education and employment center in the province is in the southeastern Avalon peninsula. Migration down the north-south gradient could possibly have reduced the effect of a north-south environmental contribution to relative risk.

This study further implicates the role of UVB exposure to humans on the ground in the etiopathogenesis of multiple sclerosis. Exposure is related to the angle of declination of the sun, absorption through the atmospheric ozone layer and the amount of cloud cover. This exposure is accurately measured using the TOMS data. However, human skin exposure is also related to the amount of clothing worn (and by implication the ambient temperature), the number of sunny days per year and the amount of time spent outdoors. Such data are available only for a small subset of regions in the province. ${ }^{45}$ Therefore, only erythemal UVB radiation at the earth's surface was modeled. Satellite UV data were available, but with relatively low resolution. With a spatial resolution of $85 \times 100 \mathrm{~km}$, a $6 \times 5$ grid of 
such "blocks" may be applied to the island of Newfoundland and its 79 census subdivisions. Therefore, resolution of UVB data is low, although linear interpolation was used for the census subdivision estimates of UVB. The gradient of average daily UVB throughout the province is approximately $10.5 \%$ (152 to 169). This is a smooth gradient from north to south given the nature of the process (angle of declination). The geospatial incidence of MS is visually variable. However, the correlations between the two are statistically significant when both local and global variation is accounted for through the conditional autoregressive model.

Vitamin D levels were not measured in our patients, but a useful extension to the current study may be to ascertain whether the risk of MS is ultimately related to the peripheral generation of vitamin D by UVB radiation. Such a study would help to confirm whether UVB is the contributor to the risk of MS or whether UVB is merely the surrogate marker for vitamin D as the contributor to risk.

\section{Conclusions}

Ultraviolet radiation has been negatively correlated with both UV exposure and residential exposure to sunlight. This study derives a negative correlation of MS incidence in the province of Newfoundland and Labrador, Canada with erythemal ultraviolet radiation (as measured by satellite) that is stronger than that obtained using latitude alone. This correlation appears to be strongest in the first year of life and declines when subsequent years are examined up to age ten. No significant correlation was found for the subjects' locale of habitation at the time of their first MS attack.

\section{ACKNOWLEDGEMENTS}

The authors thank Dr. Andrew Lawson at the Arnold School of Public Health for reviewing our Bayesian models, and Dr. William Grant from the Sunlight, Nutrition and Health Research Center for suggesting the use of the NASA TOMS data and his expertise in atmospheric science.

\section{REFERENCES}

1. Sloka J, Pryse-Phillips WE, Stefanelli M. Incidence and prevalence of Multiple Sclerosis in Newfoundland and Labrador. Can J Neurol Sci. 2005; 32(1):37-42.

2. Rahman P, Jones A, Curtis J, Bartlett S, Peddle L, Fernandez BA, et al. The Newfoundland population: a unique resource for genetic investigation of complex diseases. Hum Mol Genet. 2003; 12 Spec No 2:R167-R172.

3. Mannion JJ. The peopling of Newfoundland: essays in historic geography. St John's: Memorial University of Newfoundland; 1977.

4. Statistics Canada. 2001 Population Census. 2001

5. Sloka JS, Pryse-Phillips WE, Stefanelli M. Multiple sclerosis in Newfoundland and Labrador--a model for disease prevalence. Can J Neurol Sci. 2005; 32(1):43-9.

6. Webb AR, Holick MF. The role of sunlight in the cutaneous production of vitamin D3. Annu Rev Nutr. 1988; 8:375-99.

7. Webb AR, Kline L, Holick MF. Influence of season and latitude on the cutaneous synthesis of vitamin D3: exposure to winter sunlight in Boston and Edmonton will not promote vitamin D3 synthesis in human skin. J Clin Endocrinol Metab. 1988; 67(2):373-8.

8. Acheson ED, Bachrach CA, Wright FM. Some comments on the relationship of the distribution of multiple sclerosis to latitude, solar radiation, and other variables. Acta Psychiatr Scand. 1960; 35Suppl 147:132-47.
9. Ponsonby AL, Lucas RM, van dM, I. UVR, Vitamin D and Three Autoimmune Diseases-Multiple Sclerosis, Type 1 Diabetes, Rheumatoid Arthritis. Photochem Photobiol. 2005; 81(6): 1267-75.

10. VanAmerongen BM, Dijkstra CD, Lips P, Polman CH. Multiple sclerosis and vitamin D: an update. Eur J Clin Nutr. 2004; 58(8):1095-109.

11. Munger KL, Zhang SM, O'Reilly E, Hernan MA, Olek MJ, Willett WC, et al. Vitamin D intake and incidence of multiple sclerosis. Neurology. 2004; 62(1):60-5.

12. Pryse-Phillips WE, Sloka JS. Etiopathogenesis and epidemiology: clues to etiology. In: Cook SD, editor. Handbook of Multiple Sclerosis, 4th Ed. New York: Taylor and Francis; 2006. p.1-40.

13. Poser CM, Paty DW, Scheinberg L, McDonald WI, Davis FA, Ebers GC, et al. New diagnostic criteria for multiple sclerosis: guidelines for research protocols. Ann Neurol. 1983; 13(3): 227-31.

14. Leibowitz U, Kahana E, Alter M. The changing frequency of multiple sclerosis in Israel. Arch Neurol. 1973; 29(2):107-10.

15. Alter M, Kahana E, Loewenson R. Migration and risk of multiple sclerosis. Neurology. 1978; 28(11):1089-93.

16. Alter M, Okihiro M, Rowley W, Morris T. Multiple sclerosis among Caucasians and Orientals in Hawaii. Neurology. 1970; 20(4):399.

17. Alter M, Leibowitz U, Speer J. Risk of multiple sclerosis related to age at immigration to Israel. Arch Neurol. 1966; 15(3):234-7.

18. Dean G, Elian M. Age at immigration to England of Asian and Caribbean immigrants and the risk of developing multiple sclerosis. J Neurol Neurosurg Psychiatry. 1997; 63(5):565-8.

19. Detels R, Visscher BR, Haile RW, Malmgren RM, Dudley JP, Coulson AH. Multiple sclerosis and age at migration. Am J Epidemiol. 1978; 108(5):386-93.

20. Hammond SR, English DR, McLeod JG. The age-range of risk of developing multiple sclerosis: evidence from a migrant population in Australia. Brain. 2000; 123( Pt 5):968-74.

21. McPeters R, Krueger A, Bhartia P, Herman J. Earth Probe Total Ozone Mapping Spectrometer (TOMS) Data Products User's Guide. NASA Reference Publication. 1998-206895 1998.

22. Mollie A, Richardson S. Empirical Bayes estimates of cancer mortality rates using spatial models. Stat Med. 1991; 10(1): 95-112.

23. Besag J. Spatial interaction and the statistical analysis of lattice system. J R Stat Soc B. 1974; 36:192-236.

24. Gilks WR, Clayton DG, Spiegelhalter DJ. Modelling complexity: applications of Gibbs sampling in Medicine. J R Stat Soc B. 1993; 55:39-102.

25. Bernardinelli L, Montomoli C. Empirical Bayes versus fully Bayesian analysis of geographical variation in disease risk. Stat Med. 1992; 11(8):983-1007.

26. Clayton D, Kaldor J. Empirical Bayes estimates of age-standardized relative risks for use in disease mapping. Biometrics. 1987; 43(3):671-81.

27. Besag J, York JC, Mollie A. Bayesian image restoration with two applications in spatial statistics. Ann Inst Stat Math. 1991; 43: 1-59.

28. Pugliatti M, Solinas G, Sotgiu S, Castiglia P, Rosati G. Multiple sclerosis distribution in northern Sardinia: spatial cluster analysis of prevalence. Neurology. 2002; 58(2):277-82.

29. Geman S, Geman D. Stochastic relaxation, Gibbs distributions and the Bayesian restoration of images. IEE Trans Pattern Anal Machine Intel. 1984; 6:721-41.

30. Spiegelhalter DJ, Thomas A, Best NG, Gilks WR. BUGS: Bayesian inference using Gibbs sampling, Version 0.5. 1996. Cambridge: Medical Research Council Biostatistics Unit.

31. Breslow NE, Clayton DG. Approximate inference in generalized linear mixed models. J Am Stat Assoc. 1993; 88:9-25.

32. Geweke J. Evaluating the accuracy of sampling-based approaches to calculating marginal densities. J Am Stat Assoc. 1990; 85: 398-409. 
33. Best NG, Cowles MK, Vines SK. CODA: Convergence diagnosis and output analysis software for Gibbs sampling output, Version 0.30. 1995. Cambridge: Medical Research Council Biostatistics Unit.

34. Bernardinelli L, Clayton D, Montomoli C. Bayesian estimates of disease maps: how important are priors? Stat Med. 1995; 14(2122):2411-31.

35. Johnson GD. Small area mapping of prostate cancer incidence in New York State (USA) using fully Bayesian hierarchical modelling. Int J Health Geogr. 2004; 3(1):29.

36. Bernardinelli L, Pascutto C, Montomoli C, Gilks W. Investigating the genetic association between diabetes and malaria: an application of Bayesian ecological regression models with errors in covariates. In: Elliott P, Wakefield J, Best N, Briggs D, editors. Spatial Epidemiology: Methods and applications. Oxford: Oxford University Press, 2000.

37. Lawson A, Browne W, Vidal Rodiero C. Disease mapping with WinBUGS and MLwiN. Chichester: John Wiley and Sons, Ltd; 2003.

38. Bear JC, Nemec TF, Kennedy JC, Marshall WH, Power AA, Kolonel VM, et al. Persistent genetic isolation in outport Newfoundland. Am J Med Genet. 1987; 27(4):807-30.

39. Martin LJ, Crawford MH, Koertvelyessy T, Keeping D, Collins M, Huntsman R. The population structure of ten Newfoundland outports. Hum Biol. 2000; 72(6):997-1016.
40. Goldberg P. Multiple sclerosis: vitamin D and calcium as environmental determinanats of prevalence (a viewpoint). Part 1: sunlight, dietary factors and epidemiology. Int J Environ Studies. 1974; 6:19-27.

41. Gale CR, Martyn CN. Migrant studies in multiple sclerosis. Prog Neurobiol. 1995; 47(4-5):425-48.

42. Freedman DM, Dosemeci M, Alavanja MC. Mortality from multiple sclerosis and exposure to residential and occupational solar radiation: a case-control study based on death certificates. Occup Environ Med. 2000; 57(6):418-21.

43. van der Mei I, Ponsonby AL, Blizzard L, Dwyer T. Regional variation in multiple sclerosis prevalence in Australia and its association with ambient ultraviolet radiation. Neuroepidemiology. 2001; 20(3): 168-74.

44. van der Mei I, Ponsonby AL, Dwyer T, Blizzard L, Simmons R, Taylor BV, et al. Past exposure to sun, skin phenotype, and risk of multiple sclerosis: case-control study. BMJ. 2003; 327(7410):316.

45. Macpherson A, Macpherson J. The natural environment of Newfoundland, past and present. St John's: Department of Geography, Memorial University of Newfoundland; 2006. 